\title{
Process Monitoring and Fault Diagnosis for Shell Rolling Production of Seamless Tube
}

\author{
Dong Xiao, ${ }^{1,2}$ Xuyang Gao, ${ }^{1,2}$ Jichun Wang, ${ }^{3}$ and Yachun Mao ${ }^{4}$ \\ ${ }^{1}$ State Key Laboratory of Synthetical Automation for Process Industries, Northeast University, Shenyang 110004, China \\ ${ }^{2}$ Information Science and Engineering School, Northeastern University, Shenyang 110004, China \\ ${ }^{3}$ College of Science, Liaoning Industry University, Jinzhou 121000, China \\ ${ }^{4}$ College of Resources and Civil Engineering, Northeastern University, Shenyang 110004, China
}

Correspondence should be addressed to Dong Xiao; xiaodong@ise.neu.edu.cn

Received 6 November 2014; Revised 9 January 2015; Accepted 14 January 2015

Academic Editor: Sangmin Lee

Copyright (C) 2015 Dong Xiao et al. This is an open access article distributed under the Creative Commons Attribution License, which permits unrestricted use, distribution, and reproduction in any medium, provided the original work is properly cited.

Continuous rolling production process of seamless tube has many characteristics, including multiperiod and strong nonlinearity, and quickly changing dynamic characteristics. It is difficult to build its mechanism model. In this paper we divide production data into several subperiods by $K$-means clustering algorithm combined with production process; then we establish a continuous rolling production monitoring and fault diagnosis model based on multistage MPCA method. Simulation experiments show that the rolling production process monitoring and fault diagnosis model based on multistage MPCA method is effective, and it has a good real-time performance, high reliability, and precision.

\section{Introduction}

The deformation process of seamless tube production can be summarized into three stages: perforation, extension, and finish rolling. The main purpose of the perforation process is to perforate a solid round billet into a hollow shell. The main purpose of Elongator is to further reduce the cross section and to make the shell improve on dimensional accuracy, surface quality, and organizational performance. After elongator rolling, steel tube is called shell, which requires further molding in the finishing mill, in order to achieve the requirements of he finished tube [1]. Continuous rolling mill is an elongator which has the highest production efficiency and superior product quality. So it has been widely applied to the big steel mills. Online monitoring of operating parameters can effectively avoid accidents, eliminate equipment damage, save a lot of maintenance costs, increase running time, improve set utilization, and reduce spare parts inventory and time. Process monitoring and fault diagnosis has a very important practical significance for safe production and scientific maintenance [2].
Reference [3] analyzed the causes of roll sticking steel and gave several methods to avoid sticking steel but did not give a sticking steel monitoring method. Reference [4] introduced the rolling steel tube transverse wall and longitudinal wall thickness error monitoring method, but it needs to introduce expensive measuring instrument. Reference [5] introduced the fault diagnosis methods for DC motor of rolling roll. Reference [6] introduced a continuous rolling mill online monitoring system based on virtual instrument technology, but it monitored the variables separately and did not consider correlation between the variables, which made some deepseated faults difficult to be monitored. In the area of industrial process, significant researches have been done for online process monitoring and fault diagnosis [7-12]. Multivariate statistical analysis techniques, such as principal component analysis (PCA) [13-15] and partial least squares (PLS) [16-18], have long been used for detection and diagnosis of abnormal operating situations in many industrial processes.

Continuous rolling process is a batch process which has typical multi-period and dynamic multivariate characteristics. According to multi-period characteristics of continuous 


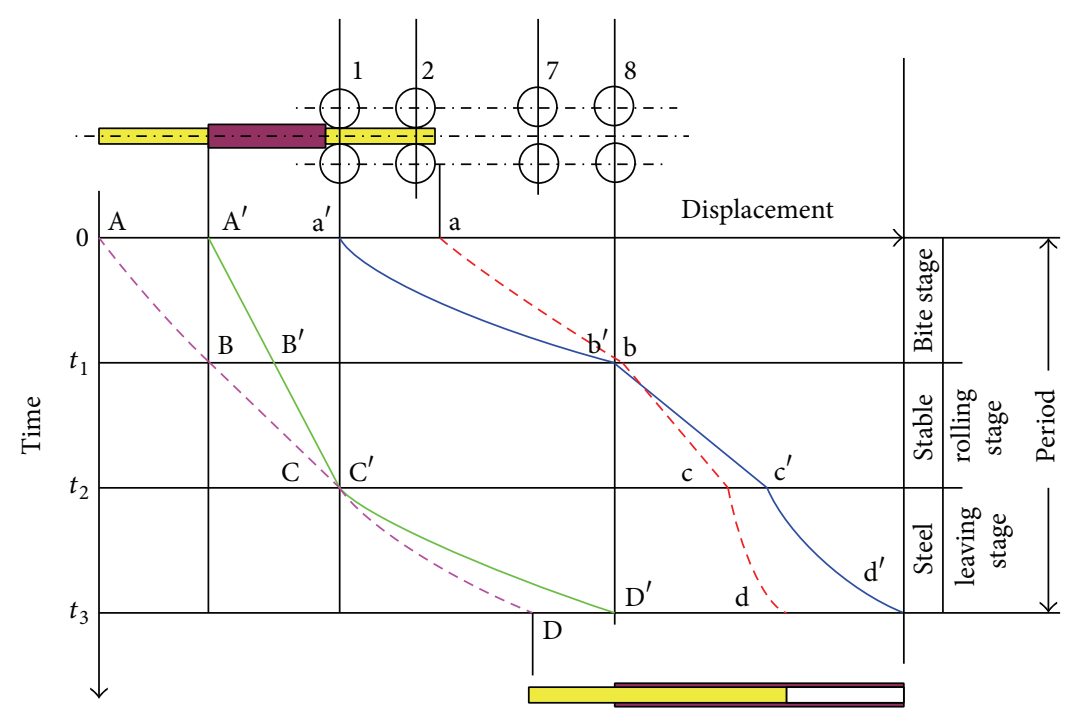

FIGURE 1: Time and displacement of rolling tube process.

rolling process, it can be divided into bite stage, stable rolling stage and steel leaving stage. The production data has the following characteristics:

(1) Large Amount of Data, High Dimension and Strong Coupling. Seamless tube rolling process is a computer supervisory and computer control industrial process. It need regularly acquire system state variables and equipment status to be used for display and control. Each cycle of seamless tube rolling production process will produce tens of thousands of process data. After accumulating, the amount of data is enormous. At the same time the behavior of the rolling process is the outcome of combining action of many variable factors which have a strong coupling relationship.

(2) Industrial Noise and Uncertainty. Because system works in complex environments, the output signal of electronic sensing devices is susceptible to noise. And it is also vulnerable to the uncertainties.

(3) Multimode. Data is a reflection of the system state changing. The data are not only in normal working state but also in various kinds of abnormal state and fault state. The former is the main part. The latter has a relatively small amount of data, but it is indispensable in the knowledge discovery and data mining.

(4) Staircase Distribution. In the biting stage the tube enters rolls from the first to the eighth, and in the steel leaving stage the situation is in turn. So the data is staircase distribution.

In this paper, by using $K$-means clustering algorithm combined with production process, we establish a continuous rolling production process monitoring and fault diagnosis model based on multistage MPCA method. Firstly, according to the production process, we divide production data into three subperiods including bite stage, stable rolling stage, and steel leaving stage. Secondly, we use clustering algorithm to further divide those larger changing stages. A satisfactory effect is difficult to be obtained if using clustering algorithm to classify the production data alone. We classify it combined with production process. Finally we get a satisfactory monitoring result. Online monitoring and fault diagnosis system not only can online monitor equipment but also can carry out fault alarm and diagnosis timely. During the monitoring process, it does not require the dedicated testers and does not need professional and technical personnel to make an analysis and judgment.

\section{Analysis of Factors Affecting the Continuous Rolling Production}

In order to build the monitoring and fault diagnosis model, we analyze the influencing factors for continuous rolling production firstly.

As shown in Figure 1, the continuous rolling process can be divided into three stages.

(1) Bite Stage. As shown in Figure 1, the head of steel tube moves from point $\mathrm{a}^{\prime}$ to point $\mathrm{b}^{\prime}$, and the tail moves from point $\mathrm{A}^{\prime}$ to point $\mathrm{B}^{\prime}$.

(2) Stable Rolling Stage. As shown in Figure 1, the head of steel tube moves from point $\mathrm{b}^{\prime}$ to point $\mathrm{c}^{\prime}$, and the tail moves from point $\mathrm{B}^{\prime}$ to point $\mathrm{C}^{\prime}$.

(3) Steel Leaving Stage. As shown in Figure 1, the head of steel tube moves from point $\mathrm{c}^{\prime}$ to point $\mathrm{d}^{\prime}$, and the tail moves from point $\mathrm{C}^{\prime}$ to point $\mathrm{D}^{\prime}$.

Factors affecting seamless steel rolling production process are mainly the following: roller rotational speed, roller input current, and roller torque.

(1) Roller Rotational Speed. In continuous rolling process, the roller rotational speed is very important. If the speed is too fast, the surface of shell cannot be completely eliminated. 


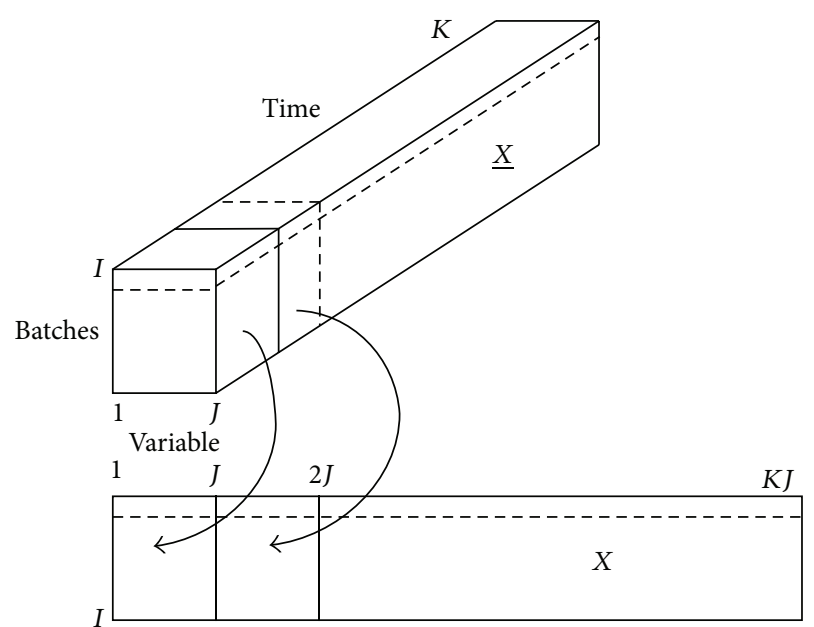

FIGURE 2: Arrangement and decomposition of a three-way array by MPCA.

In addition, if the speed is too slow, the consumption of electricity and other energy will increase.

(2) Roller Torque. The roller torque is one of the controlled variables. It is controlled by the input current. The torque directly affects the quality of steel tube. If torque is too small, it cannot completely remove the blank of tube surface. If torque is too large, shell will deform under the pressure. Reasonably controlled torque of the rolling process is an important factor which cannot be ignored. In order to save energy resources, during the wait state, the torque will be reduced. When the tube is rolled, the torque increases. When the tube leaves the roll, the torque decreases.

(3) Roller Input Current. Roller current is one of the most important control variables in the process of rolling. It is an important factor to control torque and rotational speed. Because the sensitivity of the current is higher, when the pierced tube enters the stand mill, current increases quickly. Then the roller rotational speed and roller torque increase in order to roll smoothly. Current and torque are proportional to the relationship. The current increases when the steel tube gets into the roll. Then it tends to a stable state. When the tube leaves the roll, current drops rapidly. So correctly controlling the size and direction of current is an important part of the process of rolling, and the current is the main control variable in the rolling process.

\section{Multiway Principal Component Analysis}

Batch processes are repetitive production process. Their data sets have one more dimension than the continuous production process data set. We can use three-dimensional data matrix $X=(I \times J \times K)$, instead of the batch process data collection, where the three dimensions $I, J$, and $K$, respectively, represent the batch number of samples, number of process variables, and the number of measuring points in each operation $[19,20]$. MPCA will unfold $X=(I \times J \times K)$ in such a way as to put each of its vertical slices $(I \times J)$ side by side to the right, which start with the one corresponding to the first time interval. The resulting two-dimensional matrix has dimensions $X(I \times J K)[21,22]$ (Figure 2 ).

After three-dimensional data matrix $X$ is expanded into two-dimensional data, it will be decomposed into a series of principal components consisting of score vectors $t_{j}$ and loading matrices $P_{j}$, together with a residual matrix $E$ by the principles of PCA. The MPCA model can be written as

$$
X=\sum_{j=1}^{k} t_{j} \otimes p_{j}+E,
$$

where the score vectors $t_{j}$ is related only to batches and the loading matrices $P_{j}$ is related to variables and their time variation. The noise or residual part $E$ is as small as possible in a least squares sense.

\section{Establish a Multiperiod Continuous Rolling Production Process Monitoring Model Based on K-Means and MPCA}

4.1. Collecting the Production Data. Based on actual production data characteristics of seamless steel rolling process, in this paper we use ibaAnalyzer software to collect 20 data under normal production condition. As shown in Table 1, we select 24 production process indicator variables to establish a monitoring model. In this paper, the three-dimensional data matrix is $\underline{X}(I \times J \times K)$. The three dimensions, respectively, represent the batch number of samples, number of process variables, and the number of measuring points in each operation $(I=20, J=24, K=400)$. In order to obtain vertical data slice $\widetilde{X}_{k}(I \times J)$, we cut the three-dimensional matrix along the direction of the third dimension. Thus during a period we can get 400 time slice matrixes. By using PCA for the 400 two-dimensional time slice matrix, we got 400 load matrixes and got the whole model load matrix by taking an average.

4.2. Online Monitoring Based on PCA Method. The whole PCA model can be defined as follows:

$$
P^{*}=\frac{1}{400} \sum_{k=1}^{400} \widetilde{P_{k}}
$$

where $k$ is the number of load matrix.

The number of principal components $A^{*}$ can be calculated by the cumulative contribution rate. In this paper, we set $A^{*}=6$,

$$
\text { The cumulative contribution rate }=\frac{\sum_{j=1}^{A^{*}} \lambda_{j}^{*}}{\operatorname{trace}\left(S^{*}\right)} \geq 90 \% \text {, }
$$

where $S^{*}=\operatorname{diag}\left(\lambda_{1}, \lambda_{2}, \ldots, \lambda_{J}\right)$ is an eigenvalues diagonal matrix of the matrix $\underline{X}$.

The whole PCA load matrix $P^{*}$ is divided into two parts: the main component space $\bar{P}^{*}(24 \times 6)$ and the residual 


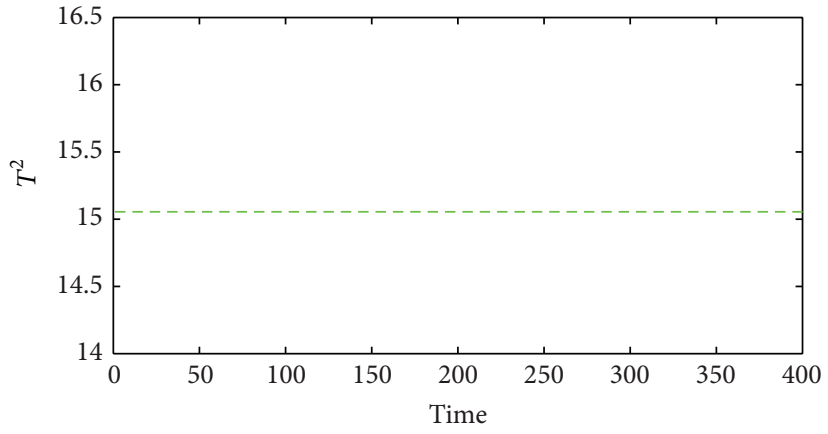

(a) $T^{2}$ control limits

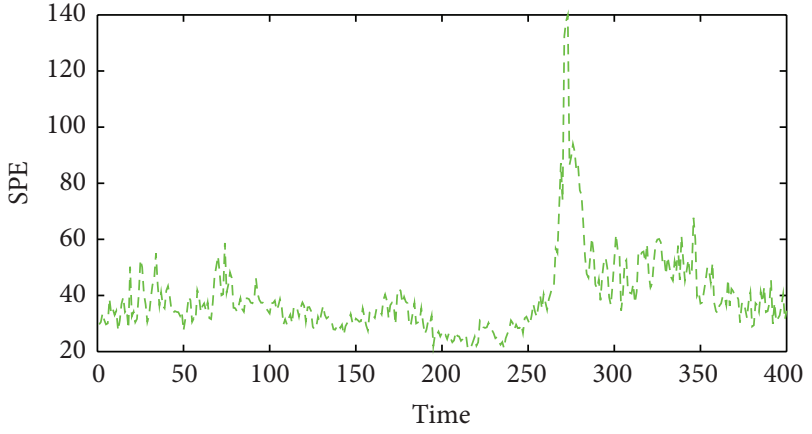

(b) SPE control limits

FIGURE 3: Seamless tube rolling process $T^{2}$ control limits and SPE control limits.

TABLE 1: Measured variables for seamless steel rolling production process.

\begin{tabular}{lcc}
\hline Symbol & Variables & $\mathrm{Unit}$ \\
\hline 1 & 1st roller speed & $\mathrm{r} / \mathrm{s}$ \\
2 & 1st roller current & $\mathrm{A}$ \\
3 & 1st roller torque & $\mathrm{N} * \mathrm{~m}$ \\
4 & 2nd roller speed & $\mathrm{r} / \mathrm{s}$ \\
5 & 2nd roller current & $\mathrm{A}$ \\
6 & 2nd roller torque & $\mathrm{N} * \mathrm{~m}$ \\
7 & 3rd roller speed & $\mathrm{r} / \mathrm{s}$ \\
8 & 3rd roller current & $\mathrm{A}$ \\
9 & 3rd roller torque & $\mathrm{N} * \mathrm{~m}$ \\
10 & 4th roller speed & $\mathrm{r} / \mathrm{s}$ \\
11 & 4th roller current & $\mathrm{A}$ \\
12 & 4th roller torque & $\mathrm{N} * \mathrm{~m}$ \\
13 & 5th roller speed & $\mathrm{r} / \mathrm{s}$ \\
14 & 5th roller current & $\mathrm{A}$ \\
15 & 5th roller torque & $\mathrm{N} * \mathrm{~m}$ \\
16 & 6th roller speed & $\mathrm{r} / \mathrm{s}$ \\
17 & 6th roller current & $\mathrm{A}$ \\
18 & 6th roller torque & $\mathrm{N} * \mathrm{~m}$ \\
19 & 7th roller speed & $\mathrm{r} / \mathrm{s}$ \\
20 & 7th roller current & $\mathrm{A}$ \\
21 & 7th roller torque & $\mathrm{N} * \mathrm{~m}$ \\
22 & 8th roller speed & $\mathrm{r} / \mathrm{s}$ \\
23 & 8th roller current & $\mathrm{A}$ \\
24 & 8th roller torque & $\mathrm{N} * \mathrm{~m}$ \\
\hline & &
\end{tabular}

space $\widetilde{\bar{P}}^{*}(24 \times 18)$. Similarly, eigenvalue diagonal matrix $S^{*}$ is correspondingly divided into two parts $\bar{S}^{*}$ and $\widetilde{\bar{S}}^{*}$

$$
\begin{aligned}
& \widetilde{T}=\widetilde{X}\left(\bar{P}^{*}\right)^{T}, \\
& \widetilde{\widetilde{X}}=\widetilde{T}\left(\bar{P}^{*}\right)^{T}, \\
& \widetilde{E}=\widetilde{X}-\widehat{\widetilde{X}} .
\end{aligned}
$$

In current online monitoring and fault diagnosis, judging whether statistics $T^{2}$ and SPE are over the limit is usually used to determine whether faults happen. The control limits of $T^{2}$ approximately obey $F$ distribution:

$$
D \sim \frac{A^{*}\left(n^{2}-1\right)}{n\left(n-A^{*}\right)} F_{A^{*}, n-A^{*}, \alpha},
$$

where $K=400$ and $n$ is the number of samples data for modeling. The control limits of $T^{2}$ is shown in Figure 3(a). For residual subspace, $\mathrm{SPE}_{k}$ of the PCA model approximately obey $\chi^{2}$ distribution $[23,24]$ at time $k$ :

$$
\begin{gathered}
\mathrm{SPE}_{k, \alpha}=g_{k} \chi_{h_{k, \alpha}}^{2}, \\
g_{k}=\frac{v_{k}}{2 m_{k}}, \\
h_{k}=\frac{2\left(m_{k}\right)^{2}}{v_{k}},
\end{gathered}
$$

where $g$ is a constant, $h$ is the freedom degree of the $\chi^{2}$ distribution, and $v_{k}$ and $m_{k}$ are, respectively, the mean and variance of the square prediction error at time $k$. SPE control limits are shown in Figure 3(b).

In order to monitor the rolling process, first we need to obtain the measured data of new production period, standardize the new data, calculate the main component and the prediction error of the data by formula (7) and check whether the $T^{2}$ and SPE are beyond their own control limit. If the statistic exceeds the control limit, it indicates that a fault may occur at the time. We now should analyze possible causes of the failure by variable $T^{2}$ and SPE time-varying contribution plots and exclude or isolate the faults. Consider

$$
\begin{gathered}
t=x \bar{P}^{*}, \\
e=x\left(I-\bar{P}^{*}\left(\bar{P}^{*}\right)^{T}\right), \\
T^{2}=t^{T}\left(\bar{S}^{*}\right)^{-1} t, \\
\text { SPE }=e e^{T} .
\end{gathered}
$$




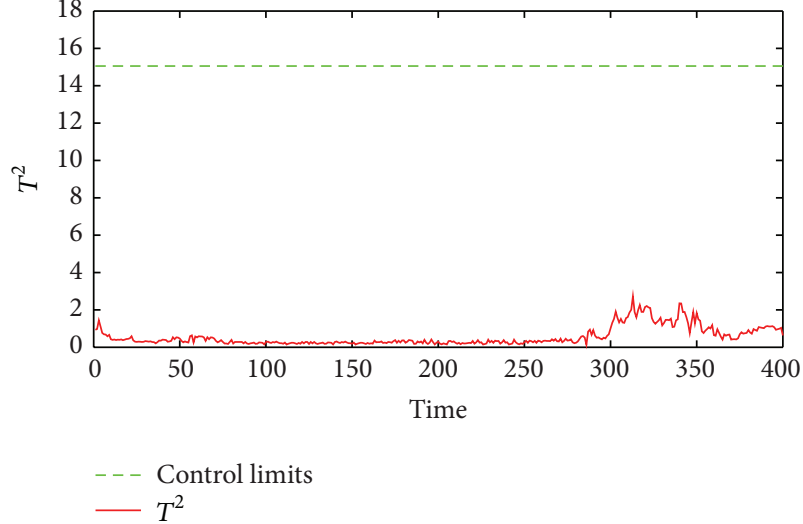

(a) $T^{2}$ monitoring plot

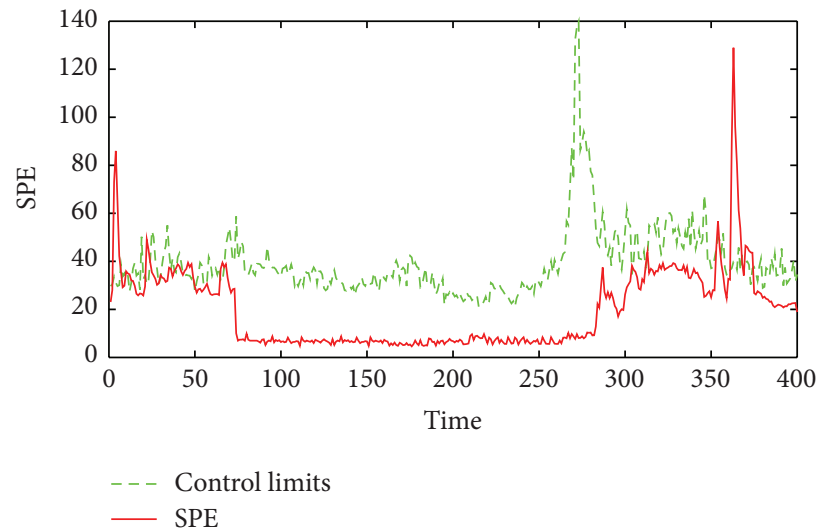

(b) SPE monitoring plot

FIGURE 4: $T^{2}$ and SPE plot for MPCA monitoring results of the normal rolling process.

As shown in Figure 4, under normal conditions, monitoring plot of SPE has an obvious alarm phenomenon during the first 50 sampling times and the last 50 sampling times. We can explain the reason for alarm in the process of monitoring combining with the rolling process. The first 50 samples are in the bite stage, where current, speed, and torque suddenly change due to steel tube enter. The last 50 samples are in the steel leaving stage, where speed, current, and torque decrease sharply because of tube leaving. Because of sudden changes of variables, standardized data still remain large deviations. Therefore, PCA monitoring model appears alarm phenomenon. So it is necessary to establish a multistage MPCA monitoring model.

4.3. Build a Multistage MPCA Monitoring Model according to Production Process. According to the process, rolling production process can be divided into three stages: bite stage, stable rolling stage, and steel leaving stage. Then this paper established a multistage MPCA monitoring model according to the three stages.

As shown in Figure 5, the situation of the steel leaving stage has improved. But alarm phenomenon still exists and the monitoring effect still needs to be improved. So the bite stage and steel leaving stage should be further divided. $K$-means and Fuzzy $C$-means (FCM) clustering algorithm are commonly used. FCM algorithm does not consider any information related to the image space continuity, so it is highly sensitive to noise. However, $K$-means algorithm is simple and fast. Particularly when dealing with the large data sets, it has a very high efficiency. So this paper chooses $K$ means clustering algorithm as a segmentation method.

\subsection{K-Means and Multistage MPCA Combined to Build a} Monitoring Model. K-means algorithm is to cluster $n$ objects based on attributes into $K(K<n)$ partitions. It assigns each object to the cluster which has the nearest center. The center is defined as the average of all the objects in the cluster, which starts from a set of random initial centers. The main steps of $K$-means clustering algorithm is as follows.
(1) Set up the cluster number $K$.

(2) Directly generate $K$ random points as cluster centers.

(3) Assign each other points to the nearest cluster center.

(4) Recalculate the new cluster centers after new points are clustered into the clusters.

(5) Repeat 3 and 4 until cluster centers do not change.

According to process and the $K$-means algorithm for segmentation, number of principal components retained in each substage PCA model is $A_{c}^{*}$, which can be obtained by formula (3). The whole PCA load matrix $P_{c}^{*}$ is divided into two parts: the main component space $\bar{P}_{c}^{*}$ and the residual space $\widetilde{\bar{P}}_{c}^{*}$, which can be obtained by formula (4). Similarly, eigenvalue diagonal matrix $S_{c}^{*}$ is correspondingly divided into two parts $\bar{S}_{c}^{*}$ and $\widetilde{\bar{S}}_{c}^{*}$. SPE control limits can be obtained by formula (4), $T^{2}$ control limits is defined as follows:

$$
D_{k} \sim \frac{A_{c}^{*}\left(n_{\text {stage } \_}^{2}-1\right)}{n_{\text {stage } c}\left(n_{\text {stage } \_}-A_{c}^{*}\right)} F_{A_{c}^{*}, n_{\text {stage } \_}-A_{c}^{*}, \alpha} .
$$

As shown in Figure 6, when the number of stages is 7 (bite stage is divided into three stages, no segmentation stable rolling stage, and steel leaving stage is divided into three stages.), $T^{2}$ and SPE are beyond their own control limits. The model has a good performance in monitoring.

According to the contrast of the foregoing analysis, we can easily conclude that seamless tube continuous rolling production process has too many characteristics, including multiperiod, strong nonlinearity, and quickly changing dynamic characteristics. It is hard to monitor production process by the traditional MPCA method. In this paper, we use multistage MPCA method, according to production process and clustering algorithm. This method can solve nonlinear problem of seamless tube rolling production process and improve the accuracy of online monitoring. At the same time the method has a strong guiding significance for the production. 


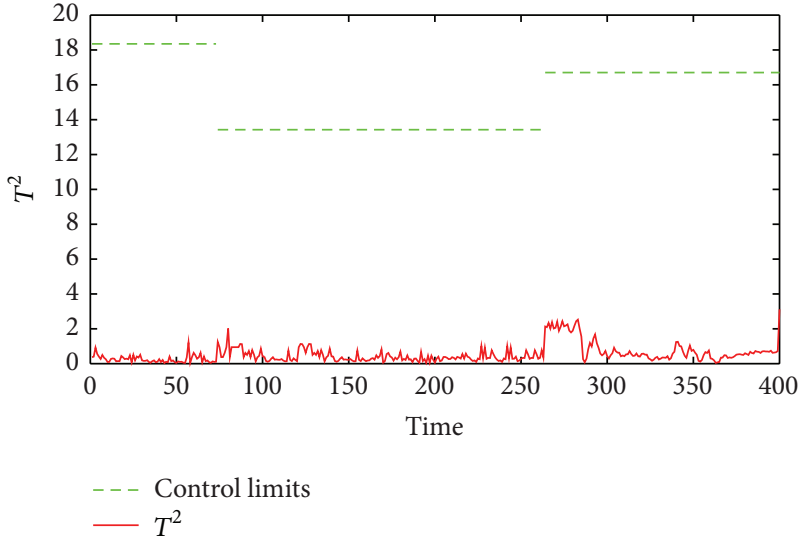

(a) $T^{2}$ monitoring plot

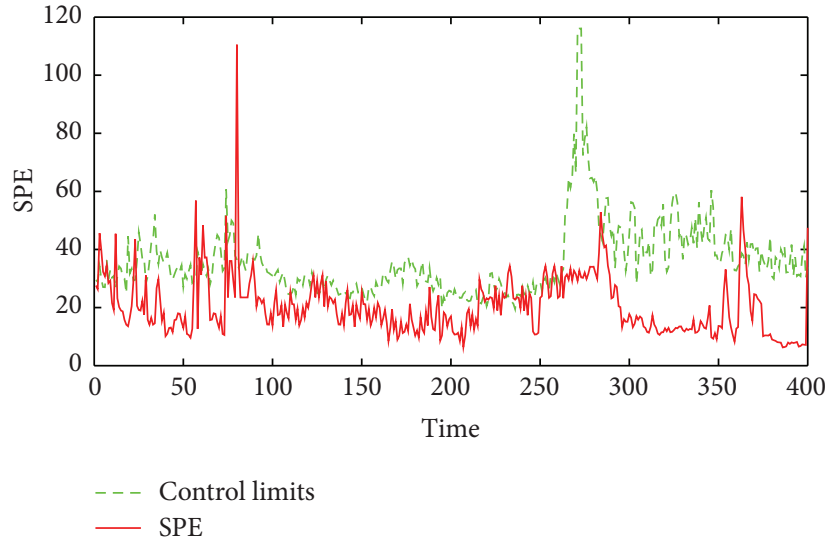

(b) SPE monitoring plot

FIgURE 5: $T^{2}$ and SPE plot for multistage MPCA monitoring results of the normal rolling process.

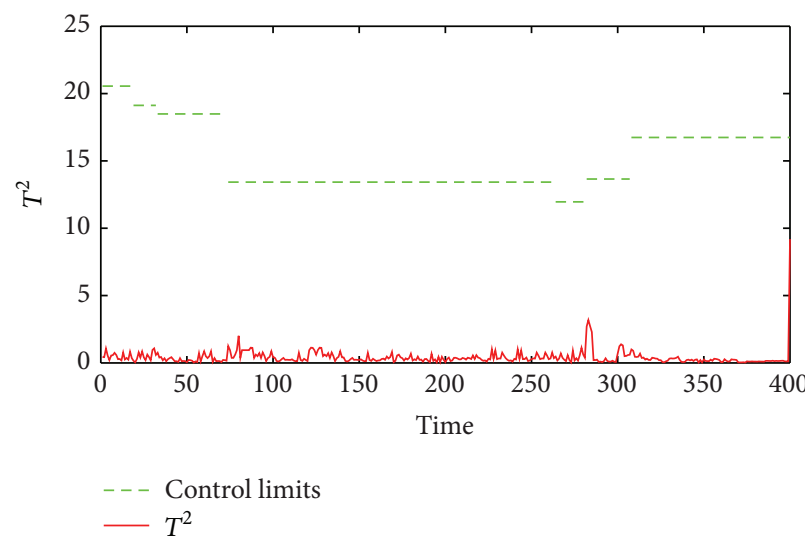

(a) $T^{2}$ monitoring plot

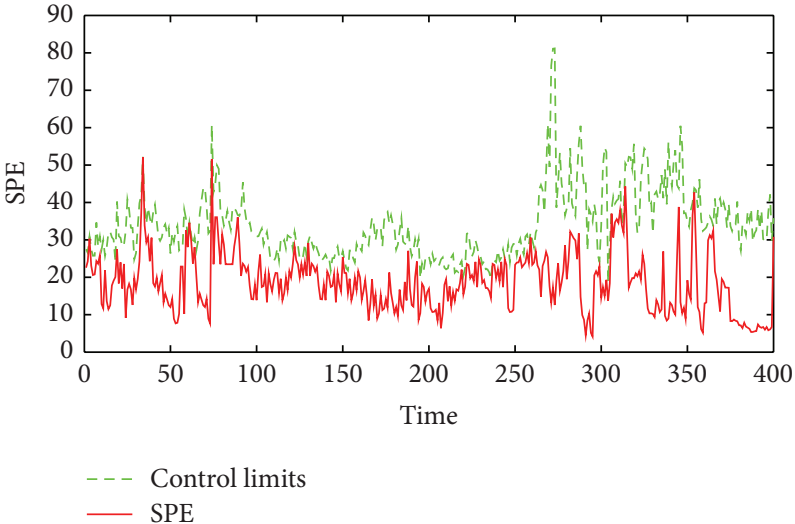

(b) SPE monitoring plot

FIGURE 6: $T^{2}$ and SPE plot for 7 stages monitoring results of the normal rolling process.

Through the experiment, we find that the number of segments is larger and the precision is higher. But at the same time it easily causes misjudgment. In this paper, after several experiments, we finally decided to select $K=7$, which both can be very good for rolling production process monitoring and avoid misjudgment. Compared with the situation without segmentation, segmentation model can more accurately judge running state of rolling process, which has a positive meaning for actual production.

\section{Fault Diagnosis}

By monitoring, the test method based on statistic can only monitor whether faults occur and the approximate time of the occurrence, but it could not determine the source of the fault. The method of contribution plot provides possibilities of determining the fault sources. It can reflect the contribution to the statistics from variables at each moment.

For the main component and residual subspace, there are two contribution plots that can be used for fault diagnosis$T^{2}$ contribution plot and SPE contribution plot.
The contribution to the $a$ th principal component $t_{a}$ from $j$ th process variable $x_{j}$ can be defined as follows:

$$
C_{t_{a}, x_{j}}=\frac{x_{j} p_{j, a}}{t_{a}} \quad(a=1, \ldots, A ; j=1, \ldots, m) .
$$

The contribution to the statistic SPE from the $j$ th process variables is

$$
C_{\mathrm{SPE}_{x_{j}}}=\frac{\left(x_{j}-\widehat{x}_{j}\right)^{2}}{\operatorname{SPE}} .
$$

In order to verify the performance of the multistage monitoring model, this paper introduces two typical fault data for monitoring and fault diagnosis.

Fault 1. 1st roller speed fault, from 75 th to 125 th sampling time, the roller speed is 0 .

Fault 2. 1st roller current fault, from 70th to 130th sampling time, the roller current is 0 . 


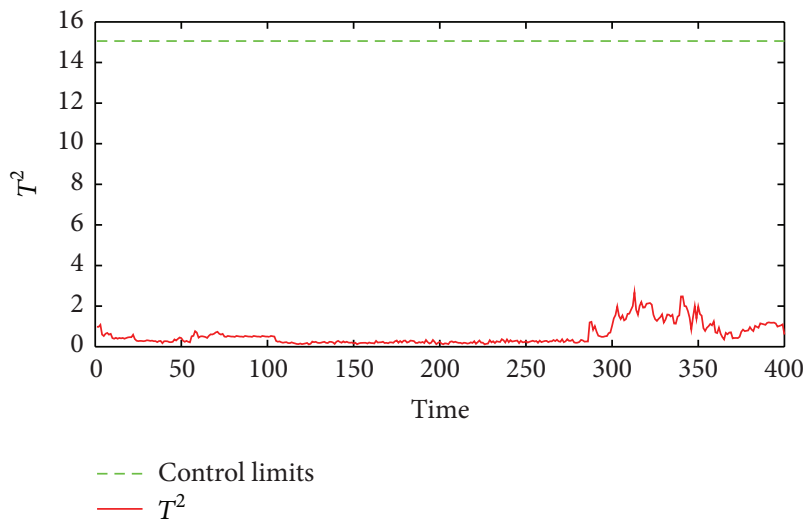

(a) $T^{2}$ monitoring plot for MPCA

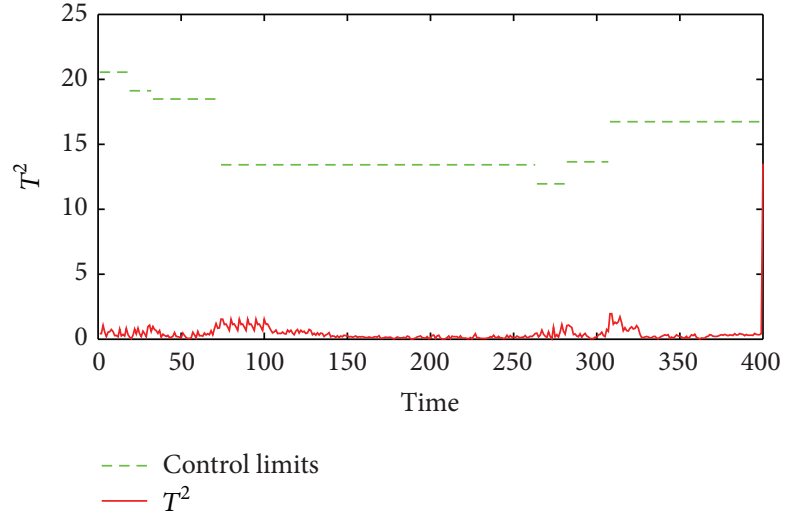

(b) $T^{2}$ monitoring plot for 7 stages MPCA

FIgURE 7: $T^{2}$ monitoring plots of fault 1 .

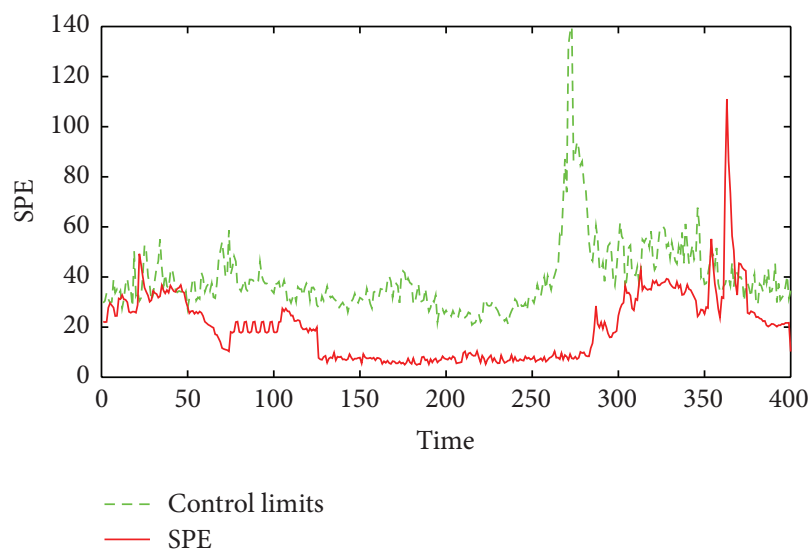

(a) SPE monitoring plot for MPCA

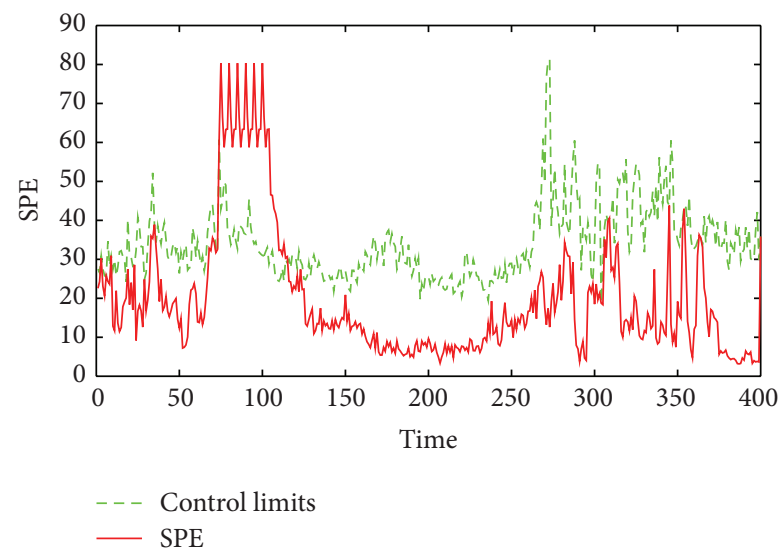

(b) SPE monitoring plot for 7 stages MPCA

FIGURE 8: SPE monitoring plots of fault 1.

5.1. Fault Diagnosis for the 1st Roller Speed. As shown in Figure 7, for fault 1, monitoring plots of SPE have an obvious alarm phenomenon, which $T^{2}$ monitoring plots do not have. For comparison, $T^{2}$ contribution plot are still drawn together with the SPE contribution plot. In order to diagnose the cause of the fault, this paper, respectively, drew main component contribution plots, $T^{2}$ contribution plots, and SPE contribution plots of 60th, 120, and 240th sampling time. As shown in Figure 8(a), MPCA model does not have an obvious alarm phenomenon in the fault time. As shown in Figure $8(\mathrm{~b})$, multistage MPCA model can quickly and accurately detect the fault.

As shown in Figure 9, the contribution rate of each principal component is not the same at different time. Near the fault time, the first principal component contribution rate was larger. Away from the fault time, the first principal component contribution rate is less than the second principal component. This paper analyzes contribution rate to the first principal component from process variables. According to contribution rate from each variable to $T^{2}$ and SPE, this paper studied and determined the fault sources. They are shown in Figures 10 and 11 .

Because $T^{2}$ monitoring plots do not have an obvious alarm phenomenon, $T^{2}$ contribution plot shown in Figure 10 does not detect the fault variable. As shown in Figure 11, in the fault time, the first variable (1st roller speed) has larger contribution rate to the first principal component. From the results we can see that SPE monitoring plots have an obvious alarm phenomenon. According to the SPE contribution rate, we can diagnose the fault. So the proposed method is correct.

5.2. Fault Diagnosis for the 1st Roller Current. As shown in Figure 12, for fault 2, monitoring plots of SPE have an obvious alarm phenomenon, which $T^{2}$ monitoring plots do not have. For comparison, $T^{2}$ contribution plots are still drawn together with the SPE contribution plot. In order to diagnose the cause of the fault, this paper, respectively, draws main component contribution plots, $T^{2}$ contribution plots, and SPE contribution plots of 50th, 125, and 250th sampling time. As shown in Figure 13(a), MPCA model does not have 


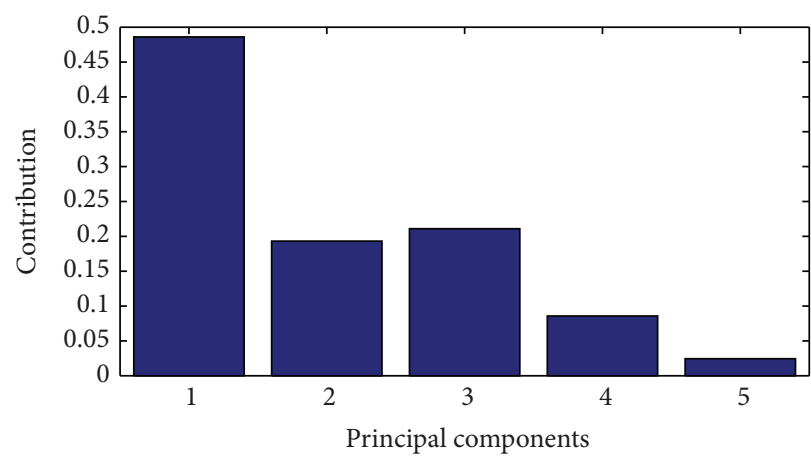

(a) Time $=60$

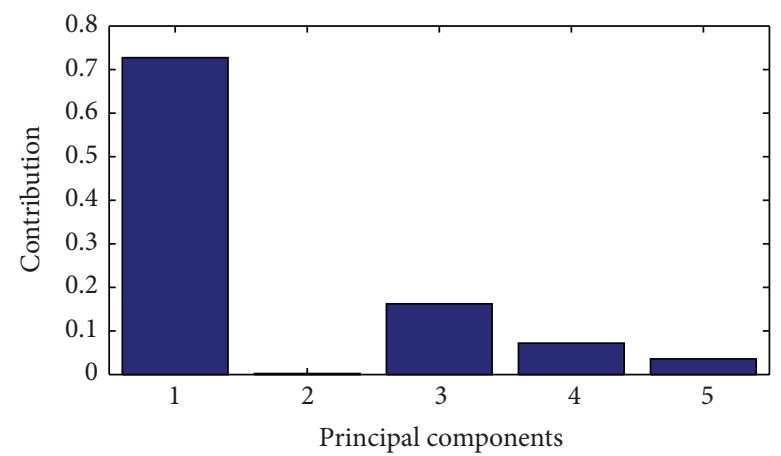

(b) Time $=120$

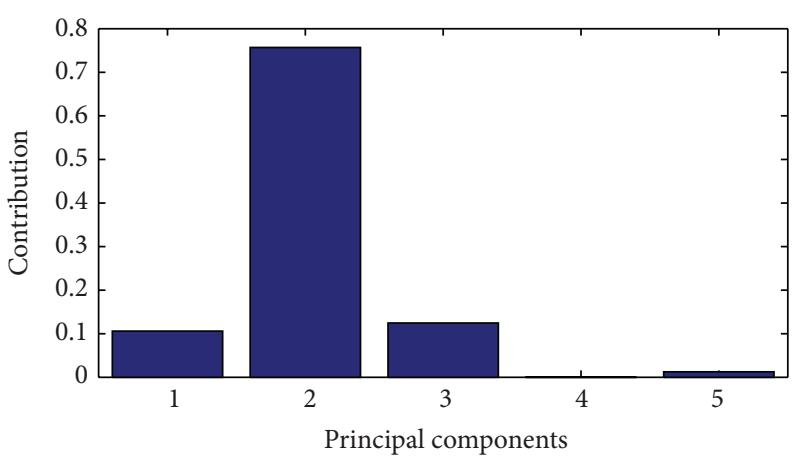

(c) Time $=240$

Figure 9: Principal component contribution plots of fault 1.

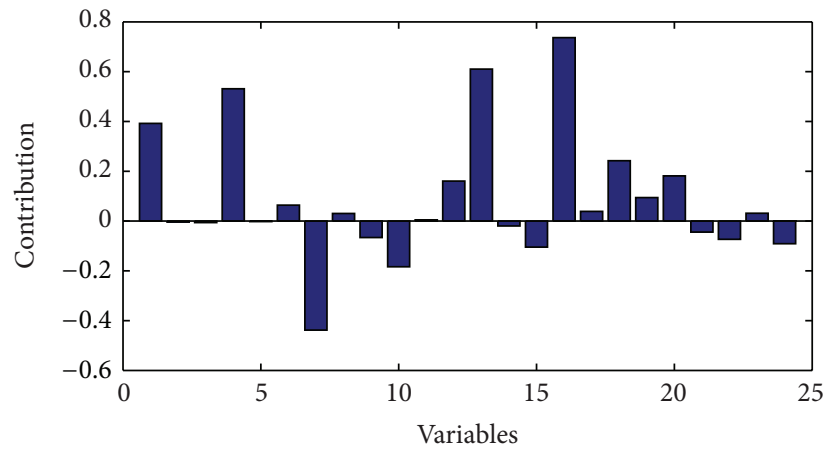

(a) Time $=60$

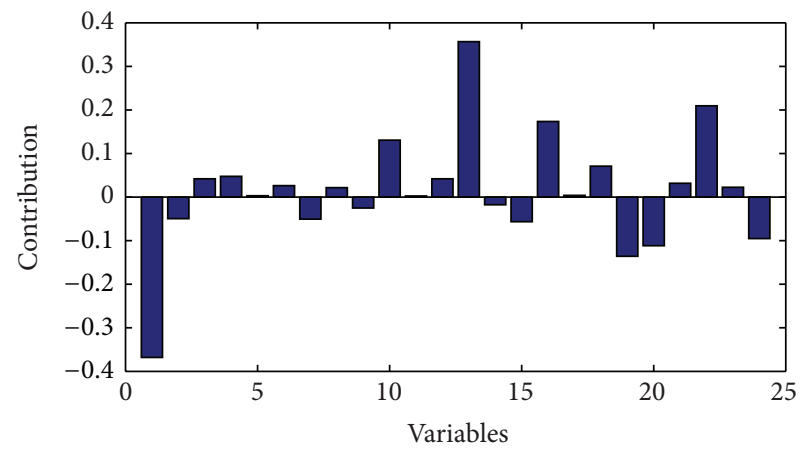

(b) Time $=120$

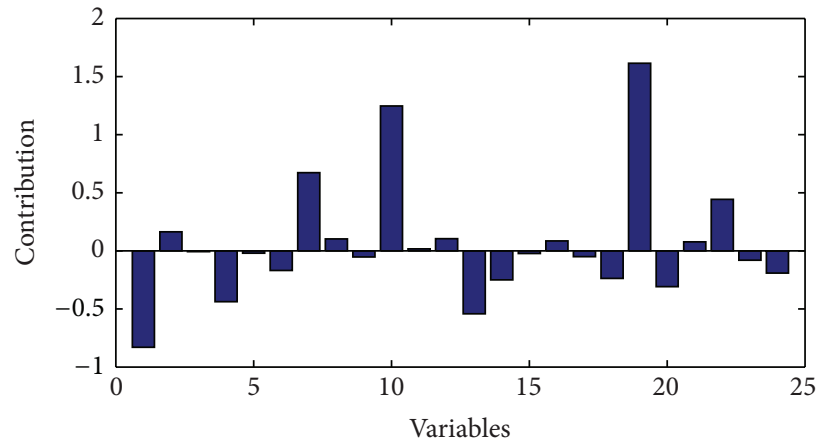

(c) Time $=240$

Figure 10: $T^{2}$ contribution plots of fault 1. 


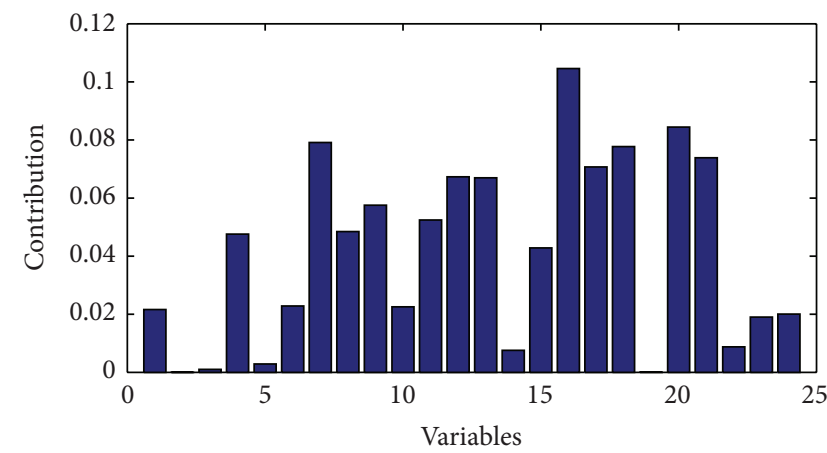

(a) Time $=60$

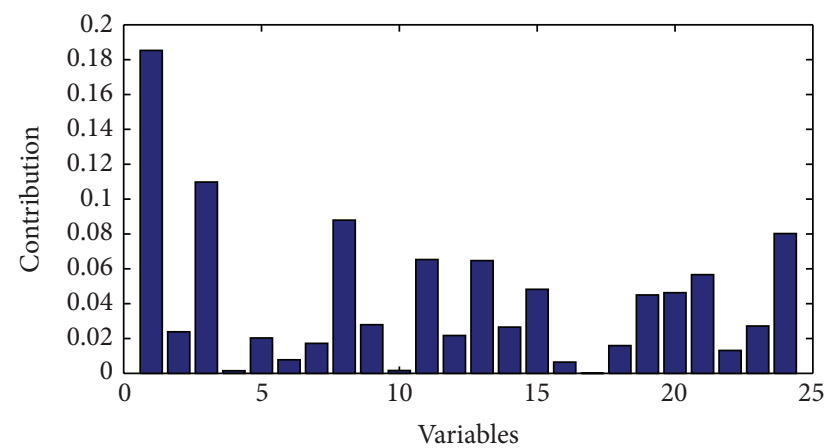

(b) Time $=120$

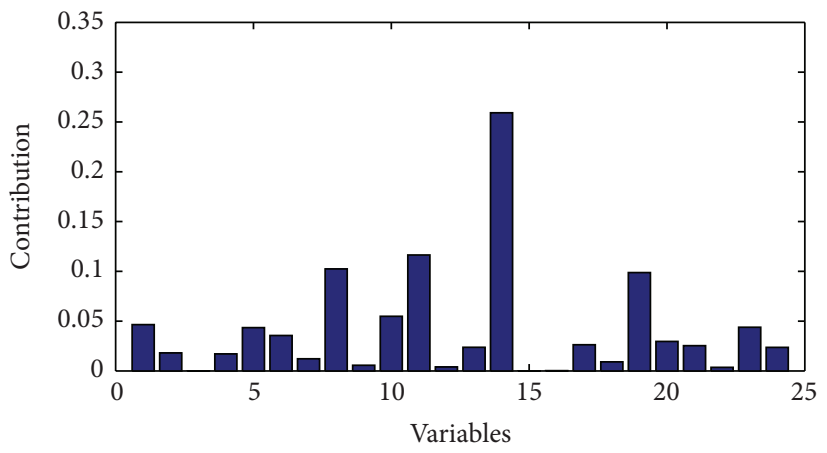

(c) Time $=240$

FIGURE 11: SPE contribution plots of fault 1.

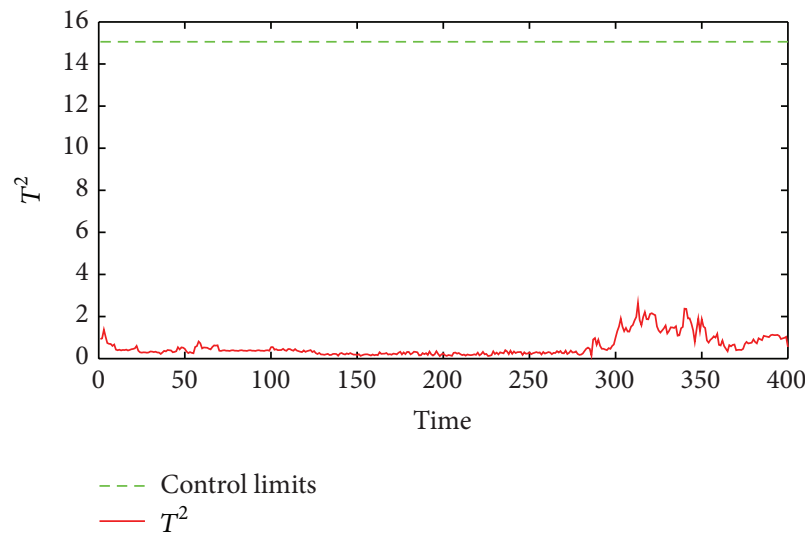

(a) $T^{2}$ monitoring plot for MPCA

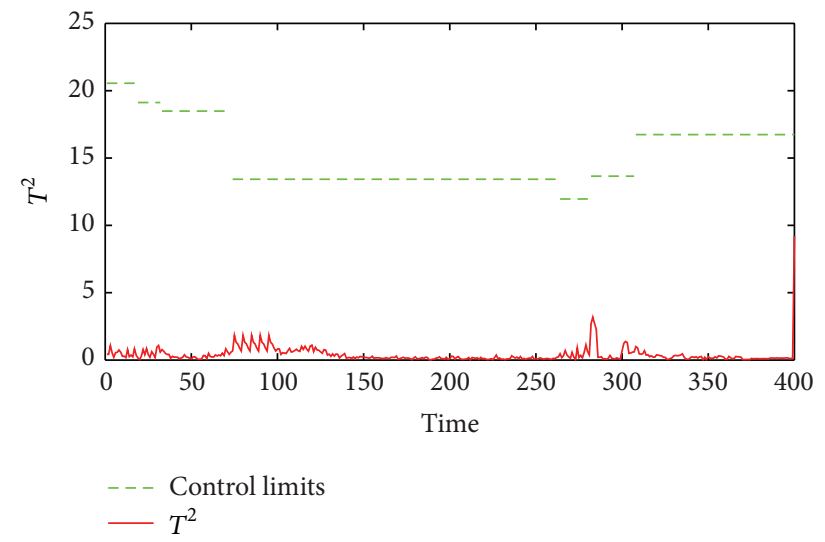

(b) $T^{2}$ monitoring plot for 7 stages MPCA

FIGURE 12: $T^{2}$ monitoring plots of fault 2.

an obvious alarm phenomenon in the fault time. As shown in Figure 13(b), multistage MPCA model can quickly and accurately detect the fault.

As shown in Figure 14, the contribution rate of each principal component is not the same at different time. Near the fault time, the first principal component contribution rate was larger. Away from the fault time, the first principal component contribution rate is less than the second principal component. This paper analyzes contribution rate to the first principal component from process variables. According to contribution rate of each variable, this paper studies and determines the fault sources. They are shown in Figures 15 and 16 .

Because $T^{2}$ monitoring plots do not have an obvious alarm phenomenon, $T^{2}$ contribution plot shown in Figure 15 does not detect the fault variable. As shown in Figure 16, in the fault time, the second variable (1st roller current) has larger contribution rate to the first principal component. From 


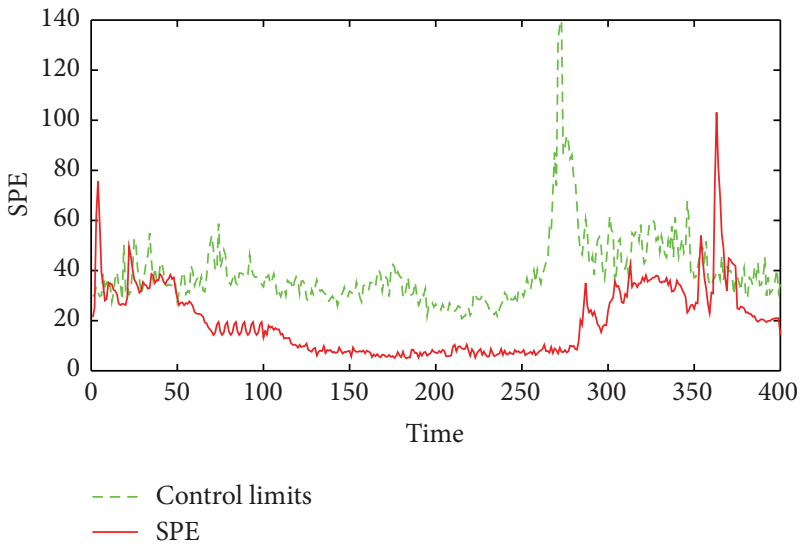

(a) SPE monitoring plot for MPCA

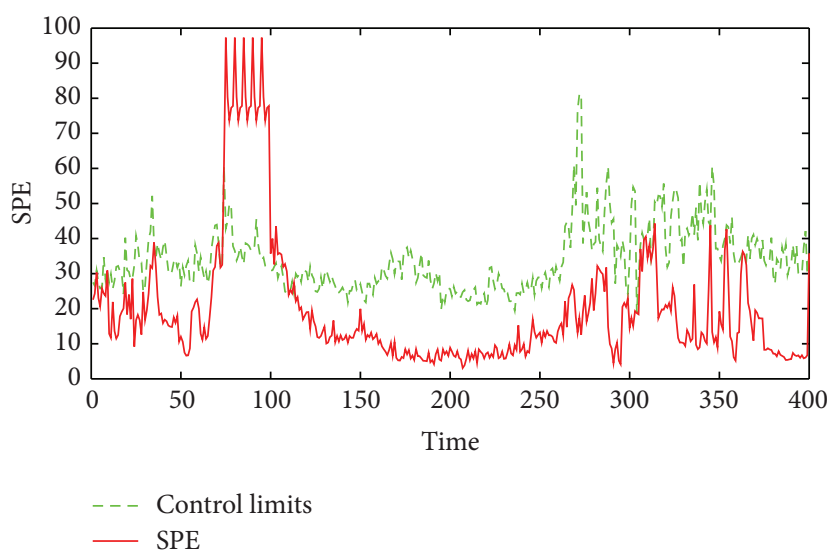

(b) SPE monitoring plot for 7 stages MPCA

FIGURE 13: SPE monitoring plots of fault 2.

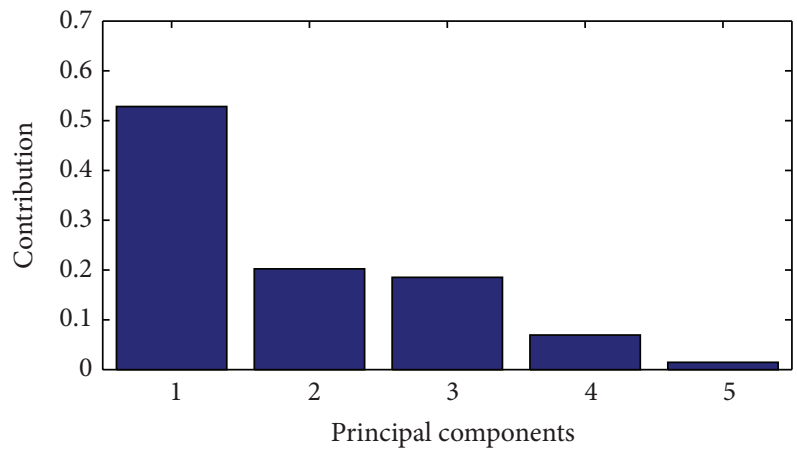

(a) Time $=50$

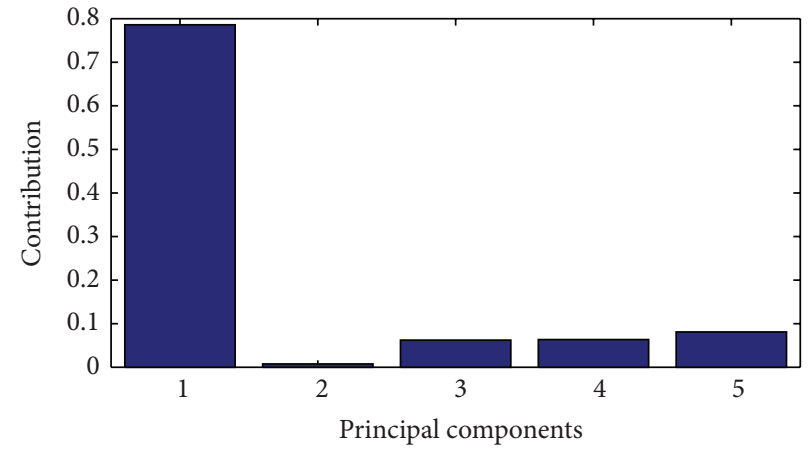

(b) Time $=125$

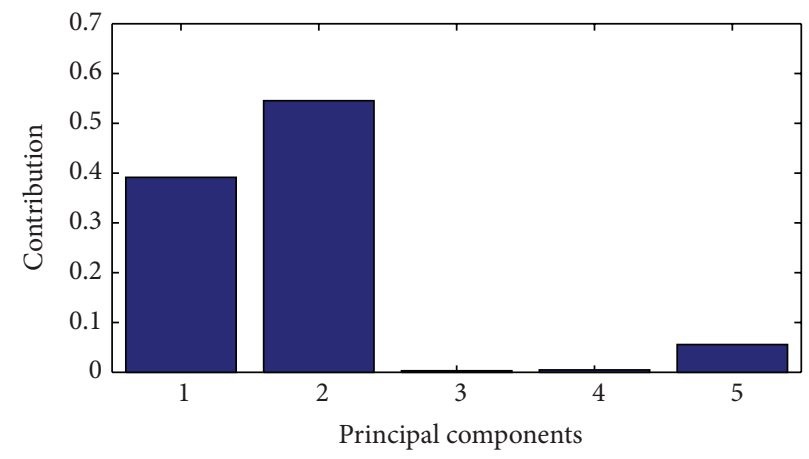

(c) Time $=250$

FIGURE 14: Principal component contribution plots of fault 2.

the results we can see that SPE monitoring plots have an obvious alarm phenomenon. According to the SPE contribution rate we can diagnose the fault. So the proposed method is correct.

\section{Conclusions}

According to strong nonlinearity and dynamic property of the seamless tube continuous rolling production process, this paper divides production data into subperiods by $K$-means clustering algorithm combined with production process. Then we establish a continuous rolling production process monitoring and fault diagnosis model based on multistage MPCA method. The results have shown that the model developed in this paper has better performances in monitoring and fault diagnosis. Meanwhile the proposed method can be extended to the other industry processes. 


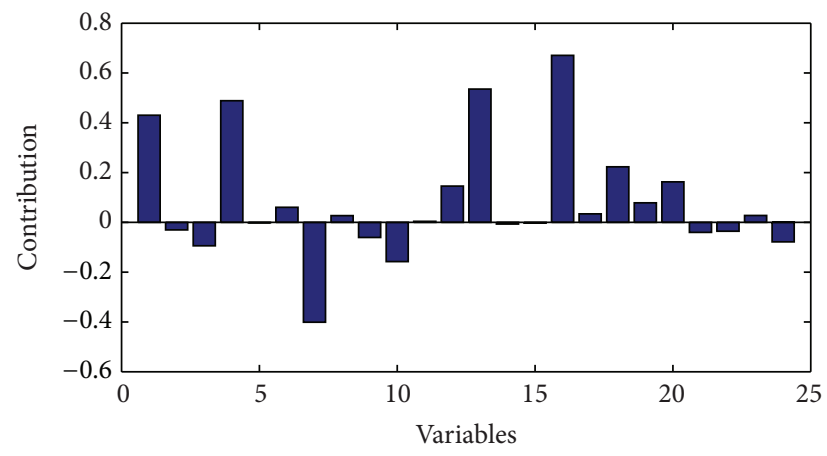

(a) Time $=50$

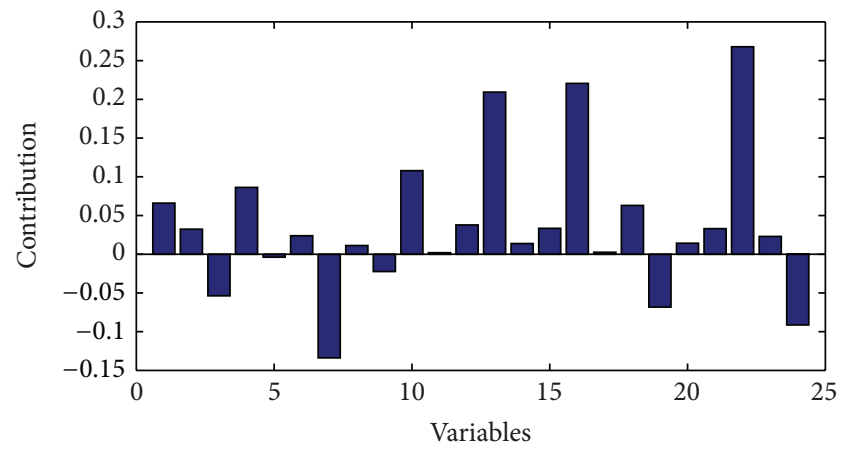

(b) Time $=125$

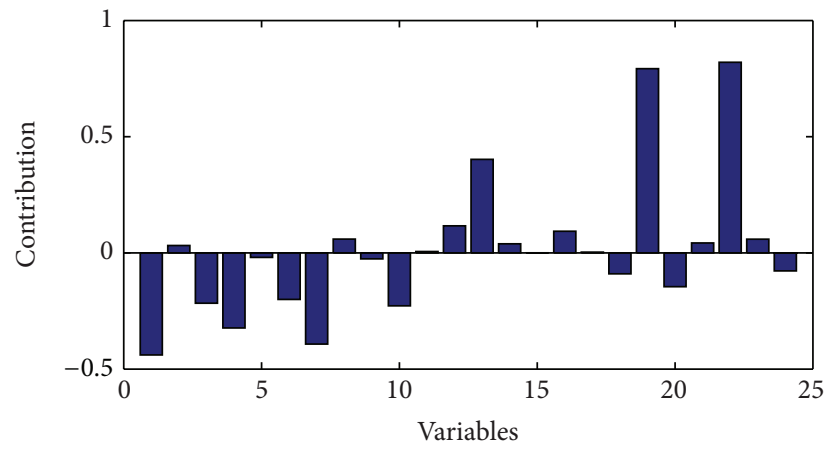

(c) Time $=250$

FIGURE 15: $T^{2}$ contribution plots of fault 2.

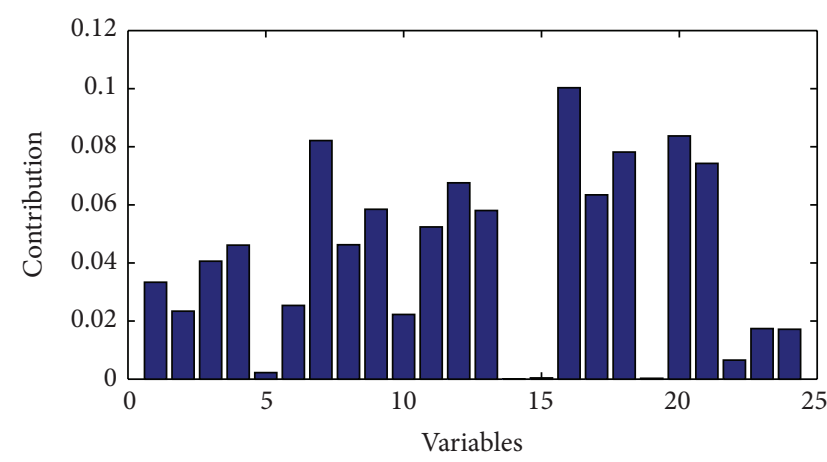

(a) Time $=50$

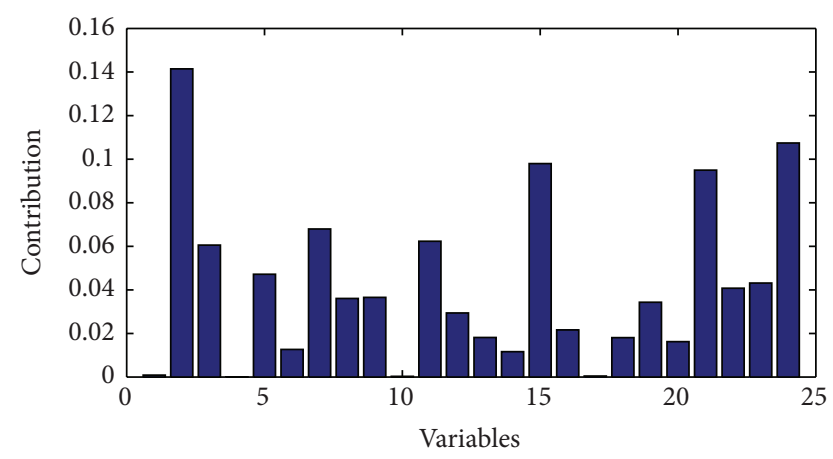

(b) Time $=125$

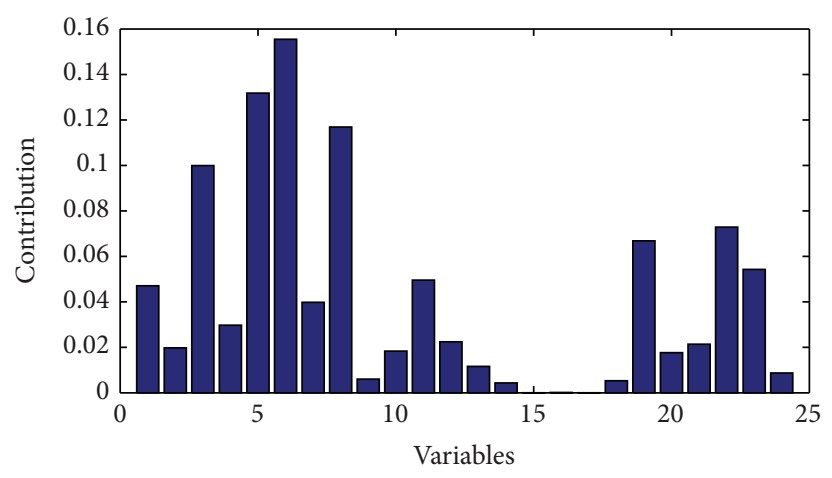

(c) Time $=250$

FIgURE 16: SPE contribution plots of fault 2. 


\section{Conflict of Interests}

The authors declare that there is no conflict of interests regarding the publication of this paper.

\section{Acknowledgments}

This research is supported by National Natural Science Foundation of China (Grant no. 61203214), Provincial Science and Technology Department of Education projects the general project (L2013101), and National Natural Science Foundation of China (Grant nos. 41371437, 61403277, 61304121, 61473072, 61203103, and 61374146).

\section{References}

[1] D. Xiao, J. C. Wang, and H. X. Tian, "Quality prediction and control of reducing pipe based on EOS-ELM-RPLS mathematics modeling method," Journal of Applied Mathematics, vol. 2014, Article ID 298218, 13 pages, 2014.

[2] D. Lévesque, S. E. Kruger, G. Lamouche et al., "Thickness and grain size monitoring in seamless tube-making process using laser ultrasonics," NDT \& E International, vol. 39, no. 8, pp. 622626, 2006.

[3] Y. Lv, Y. R. Li, and H. G. Wang, "On-line monitoring and fault diagnosis for mill drives," Heavy Machinery, vol. 2002, no. 2, pp. 56-59, 2002.

[4] M. Reggio, F. McKenty, L. Gravel, J. Cortes, G. Morales, and M.-A. Ladron de Guevara, "Computational analysis of the process for manufacturing seamless tubes," Applied Thermal Engineering, vol. 22, no. 4, pp. 459-470, 2002.

[5] H. Jin, Fault Diagnosis of Large DC Motor Strip Mill, University of Science and Technology of China, 2000.

[6] L. Lei and H. L. Zhang, "Continuous rolling-tube unit on-line supervision system based on virtual instrument technology," Natural Science Journal of Xiangtan University, vol. 26, no. 1, pp. 102-105, 2004.

[7] C. H. Zhao and F. R. Gao, "Fault-relevant Principal Component Analysis (FPCA) method for multivariate statistical modeling and process monitoring," Chemometrics and Intelligent Laboratory Systems, vol. 133, no. 1, pp. 1-12, 2014.

[8] J. Yu, "Local and nonlocal preserving projection for bearing defect classification and performance assessment," IEEE Transactions on Industrial Electronics, vol. 59, no. 5, pp. 2363-2376, 2012.

[9] B. Zhang, C. Sconyers, C. Byington, R. Patrick, M. E. Orchard, and G. Vachtsevanos, "A probabilistic fault detection approach: application to bearing fault detection," IEEE Transactions on Industrial Electronics, vol. 58, no. 5, pp. 2011-2018, 2011.

[10] S. Yin, S. X. Ding, A. Haghani, H. Hao, and P. Zhang, "A comparison study of basic data-driven fault diagnosis and process monitoring methods on the benchmark Tennessee Eastman process," Journal of Process Control, vol. 22, no. 9, pp. 1567-1581, 2012.

[11] S. X. Ding, "Data-driven design of monitoring and diagnosis systems for dynamic processes: a review of subspace technique based schemes and some recent results," Journal of Process Control, vol. 24, no. 2, pp. 431-449, 2014.

[12] Y. Lei, J. Lin, Z. He, and M. J. Zuo, "A review on empirical mode decomposition in fault diagnosis of rotating machinery,"
Mechanical Systems and Signal Processing, vol. 35, no. 1-2, pp. 108-126, 2013.

[13] S. Bedoui, R. Faleh, H. Samet, and A. Kachouri, "Electronic nose system and principal component analysis technique for gases identification," in Proceedings of the 10th International MultiConference on Systems, Signals \& Devices (SSD '13), pp. 1-6, IEEE, Hammamet, Tunisia, March 2013.

[14] G. Georgoulas, M. O. Mustafa, I. P. Tsoumas et al., "Principal Component Analysis of the start-up transient and Hidden Markov Modeling for broken rotor bar fault diagnosis in asynchronous machines," Expert Systems with Applications, vol. 40, no. 17, pp. 7024-7033, 2013.

[15] M. Evans and J. Kennedy, "Integration of adaptive neuro fuzzy inference systems and principal component analysis for the control of tertiary scale formation on tinplate at a hot mill," Expert Systems with Applications, vol. 41, no. 15, pp. 6662-6675, 2014.

[16] C. M. Ringle, M. Sarstedt, R. Schlittgen, and C. R. Taylor, "PLS path modeling and evolutionary segmentation," Journal of Business Research, vol. 66, no. 9, pp. 1318-1324, 2013.

[17] E. M. Abdel-Rahman, O. Mutanga, J. Odindi, E. Adam, A. Odindo, and R. Ismail, "A comparison of partial least squares (PLS) and sparse PLS regressions for predicting yield of Swiss chard grown under different irrigation water sources using hyperspectral data," Computers and Electronics in Agriculture, vol. 106, pp. 11-19, 2014.

[18] B. Lu, I. Castillo, L. Chiang, and T. F. Edgar, "Industrial PLS model variable selection using moving window variable importance in projection," Chemometrics and Intelligent Laboratory Systems, vol. 135, no. 15, pp. 90-109, 2014.

[19] N. Lu, F. Gao, and F. Wang, "Sub-PCA modeling and on-line monitoring strategy for batch processes," AIChE Journal, vol. 50, no. 1, pp. 255-259, 2004.

[20] X.-T. Doan, R. Srinivasan, P. M. Bapat, and P. P. Wangikar, "Detection of phase shifts in batch fermentation via statistical analysis of the online measurements: a case study with rifamycin B fermentation," Journal of Biotechnology, vol. 132, no. 2, pp. 156-166, 2007.

[21] M. Emparán, R. Simpson, S. Almonacid, A. Teixeira, and A. Urtubia, "Early recognition of problematic wine fermentations through multivariate data analyses," Food Control, vol. 27, no. 1, pp. 248-253, 2012.

[22] W. Dong, Y. Yao, and F. Gao, "Phase analysis and identification method for multiphase batch processes with partitioning multiway principal component analysis (MPCA) model," Chinese Journal of Chemical Engineering, vol. 20, no. 6, pp. 1121-1127, 2012.

[23] P. Nomikos and J. F. MacGregor, "Multi-way partial least squares in monitoring batch processes," Chemometrics and Intelligent Laboratory Systems, vol. 30, no. 1, pp. 97-108, 1995.

[24] Y. S. Qi, P. Wang, X. J. Gao, and Y. J. Gong, "Batch process monitoring and fault diagnosis based on improved multi-way principal component analysis," CIESC Journal, vol. 85, no. 1, pp. 82-93, 2009. 


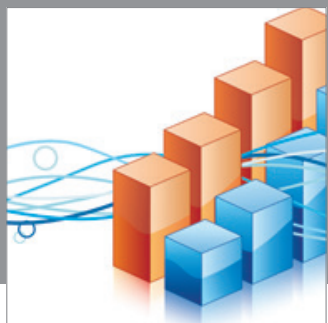

Advances in

Operations Research

mansans

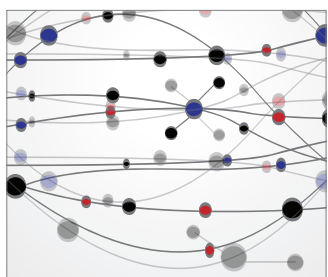

The Scientific World Journal
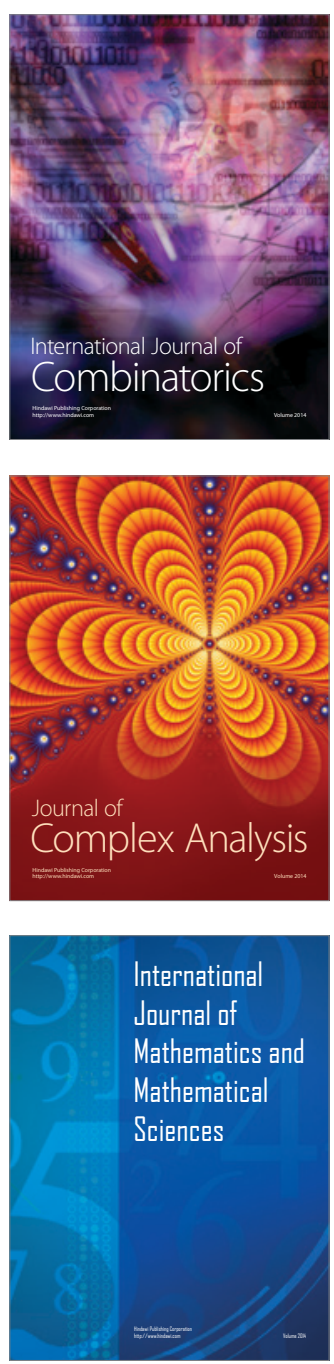
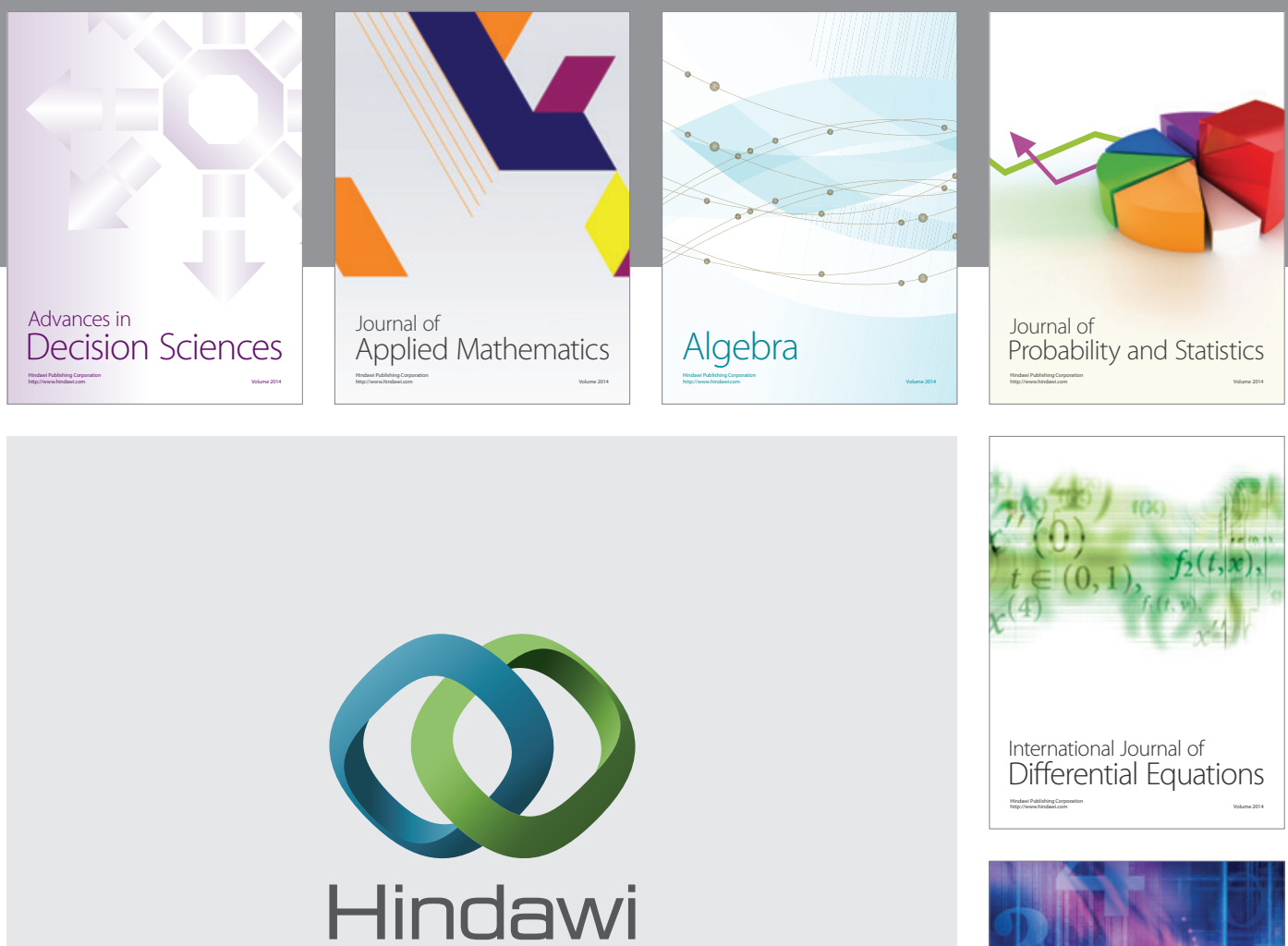

Submit your manuscripts at http://www.hindawi.com
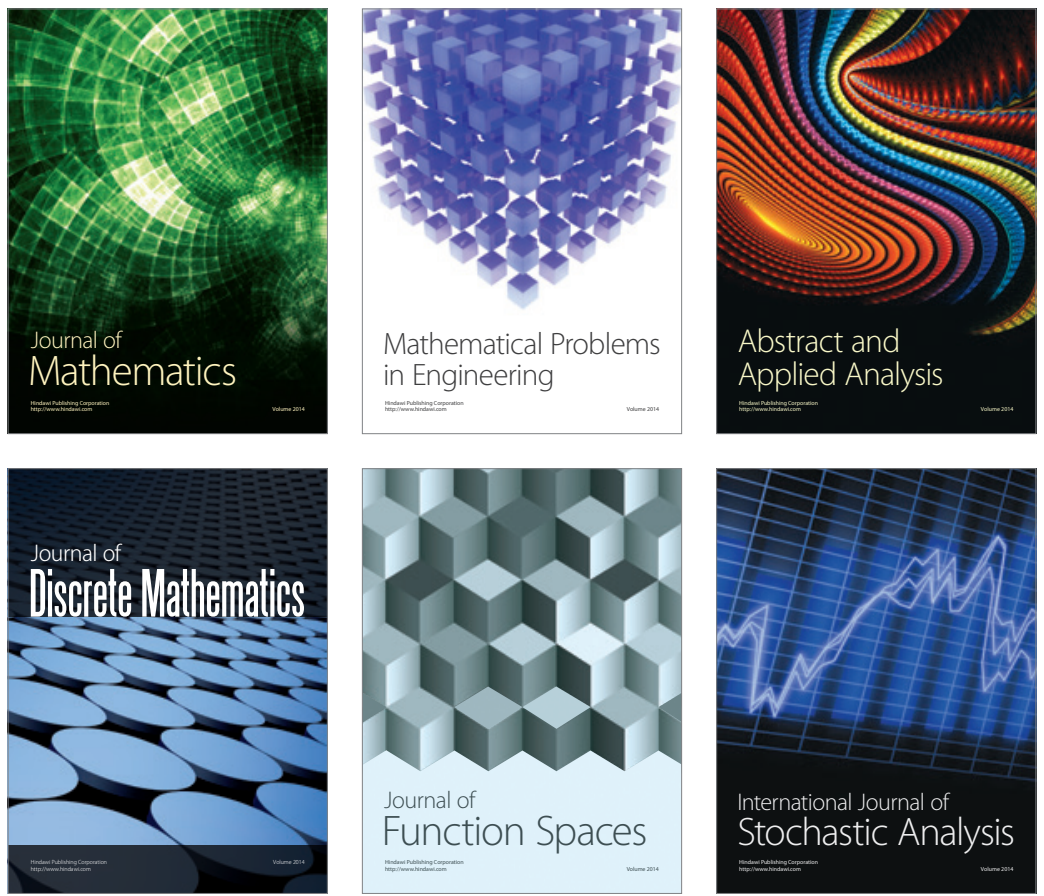

Journal of

Function Spaces

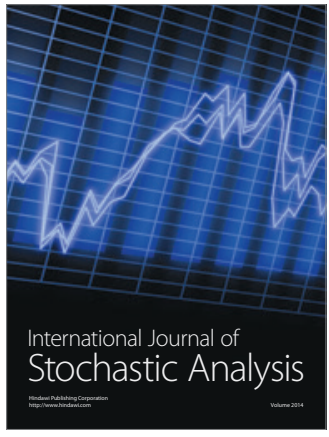

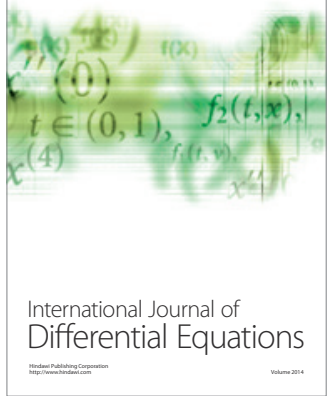
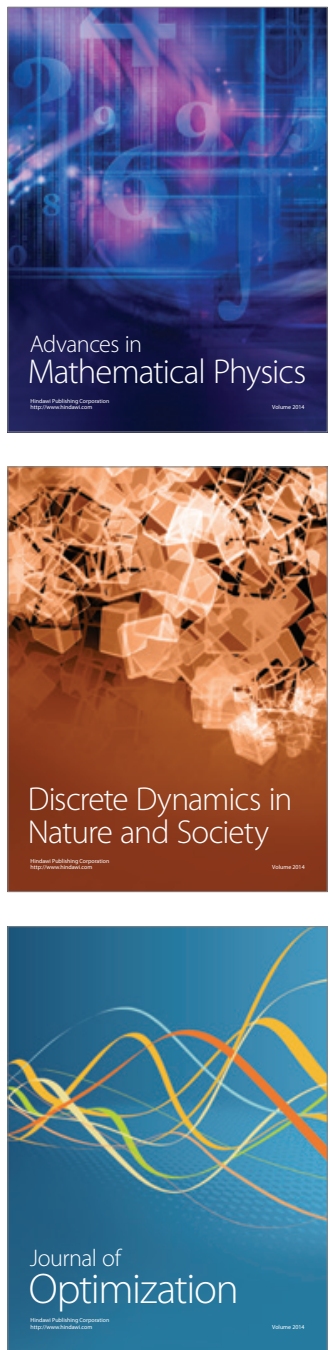